\title{
Antibiotic Resistance in the Alternative Lifestyles of Campylobacter jejuni
}

\begin{abstract}
Daise Aparecida Rossi ${ }^{1}$, Carolyne Ferreira Dumont ${ }^{1}$, Ana Carolina de Souza Santos ${ }^{2}$, Maria Eduarda de Lourdes Vaz ${ }^{2}$, Renata Resende Prado ${ }^{1}$, Guilherme Paz Monteiro ${ }^{1}$, Camilla Beatriz da Silva Melo ${ }^{2}$, Vassiliki Jaconi Stamoulis ${ }^{2}$, Jandra Pacheco dos Santos ${ }^{3}$ and Roberta Torres de Melo ${ }^{1 *}$

${ }^{1}$ Laboratory of Molecular Epidemiology, Faculty of Veterinary Medicine, Federal University of Uberlândia, Uberlândia, Brazil, 2 Laboratory of Cellular and Molecular Biology, Faculty of Veterinary Medicine, University of Uberaba, Uberaba, Brazil,

${ }^{3}$ Multidisciplinary Laboratory, Department of Veterinary Medicine, Goiás University Center, Goiânia, Brazil
\end{abstract}

\section{OPEN ACCESS \\ Edited by:}

Guillermo Ignacio Perez, New York University, United States

Reviewed by: Anja Klančnik,

University of Ljubljana, Slovenia Hosny El-Adawy,

Friedrich Loeffler Institut, Germany

*Correspondence:

Roberta Torres de Melo roberta-melo@hotmail.com

Specialty section:

This article was submitted to Clinical Microbiology, a section of the journal

Frontiers in Cellular and Infection Microbiology

Received: 17 February 2020 Accepted: 21 April 2021 Published: 13 May 2021

Citation:

Rossi DA, Dumont CF, Santos ACdS, Vaz MEdL, Prado RR, Monteiro GP, Melo CBdS, Stamoulis VJ, Santos JPd and Melo RTd (2021) Antibiotic Resistance in the Alternative Lifestyles of Campylobacter jejuni. Front. Cell. Infect. Microbiol. 11:535757. doi: 10.3389/fcimb.2021.535757
Campylobacter jejuni is the main pathogen identified in cases of foodborne gastroenteritis worldwide. Its importance in poultry production and public health is highlighted due to the growing antimicrobial resistance. Our study comparatively investigated the effect of five different classes of antimicrobials on the planktonic and biofilm forms of 35 strains of $C$. jejuni with high phylogenetic distinction in 30 of them. In the planktonic form, the existence of susceptible strains to colistin (7/35 - 20\%) and resistance to meropenem (3/35 - 8.6\%) represent a novelty in strains evaluated in Brazil. In biofilms formed with the addition of chicken juice, the number of resistant strains was significantly higher for colistin, erythromycin and meropenem (100\%), but the susceptibility to tetracycline was shown as a control strategy for specific cases. High concentrations $(1,060 \pm 172.1 \mathrm{mg} / \mathrm{L})$ of antibiotics were necessary to control the biofilm structure in susceptible strains in the planktonic form, which is consistent with the high biomass produced in these strains. Stainless steel and polyurethane were the most $(B F I=2.1)$ and least $(B F I=1.6)$ favorable surfaces for the production of biomass treated with antimicrobials. It is concluded that the antimicrobial action was detected for all tested drugs in planktonic form. In sessile forms, the biomass production was intensified, except for tetracycline, which showed an antibiofilm effect.

Keywords: campylobacteriosis, meropenem, SEM, tetracycline, biofilm

\section{INTRODUCTION}

Campylobacter jejuni is considered the main pathogen that causes human foodborne gastroenteritis worldwide, commonly found in the gastrointestinal tract of broilers. It is responsible for more than 500 million cases of diarrhea every year (CDC, 2020; EFSA, 2020) and in severe cases of infection by C. jejuni, individuals can develop post-infection complications such as Guillain Barré Syndrome (Goodfellow and Wilson, 2016).

Despite being considered a fastidious microorganism, $C$. jejuni has a high potential to produce biofilms, and thus survive and multiply in its hosts and in the environment (WHO, 2017a). This 
lifestyle provides greater adaptation to adverse conditions, including resistance to antimicrobials (Klein-Jobstl et al., 2016; Tang et al., 2017).

Biofilms are sets of microbial cells attached to biotic or abiotic surfaces involved in an extracellular matrix that significantly reduces susceptibility to antimicrobial agents when compared to planktonic cells. Sessile cell-related infections are, as a result, extremely difficult to treat. The low antimicrobials interaction with the biofilm matrix that prevents access to bacteria, reduction of multiplication rate and bacterial metabolism, and the intrinsic or plasmidial determinants of antibiotic resistance contribute to this profile and help ensure the survival of biofilm cells even under more aggressive antimicrobial treatment regimes (Hall and Mah, 2017). In addition, the presence of these structures in equipment and processing surfaces, such as stainless steel, polypropylene and polyurethane, become a persistent reservoir of contamination, compromising food safety and human health (Arnold and Silvers, 2000).

The indiscriminate use of antibiotics to fight infectious diseases has led to the emergence of many antibiotic-resistant bacteria, which have become a global problem in public health. Over the past years, several studies have reported these problem in C. jejuni strains (Melo et al., 2019; Elhadidy et al., 2020). For C. jejuni, the increase in the resistance profile over time is also associated with veterinary practices in the control of pathogens in birds. Antibiotics released in poultry production environments can interfere with the development of resistance profiles and affect the characteristics of bacterial biofilms or benefit the maintenance of the sessile life form, including $C$. jejuni, which produces highly stable and mature biofilms when in the chicken juice (CJ) presence (Melo et al., 2017).

Concerns are growing due to the current classification of C. jejuni by the WHO as a "high priority pathogen" due to the emergence of resistance to multiple drugs such as those belonging to the fluoroquinolone, macrolides, and other classes (Iovine, 2013; WHO, 2017b), which limits the treatment alternatives.

Given the impact of campylobacteriosis on public health, Brazil's leading position as the world's largest chicken meat exporter and the emergence of antimicrobial resistance in Campylobacter (Perio et al., 2013; EFSA-ECDC, 2015; WHO, 2017a; ABPA, 2020), it is necessary to constantly monitor the characteristics of this agent.

Our study investigated the differences in susceptibility to antibiotics, with different mechanisms of action, in C. jejuni isolated from chicken carcasses in planktonic and biofilm forms in the presence of CJ under different abiotic surfaces.

\section{MATERIAL AND METHODS}

\section{Strains}

Thirty-five strains of $C$. jejuni were used from the analysis from 442 carcasses of chilled or frozen chicken carcasses, ready for commercialization, isolated from September of 2015 to March of 2016, from the Brazilian poultry industry. The chickens were slaughtered in three different states (Minas Gerais, Goiás and Distrito Federal), in slaughterhouses authorized for export and under the supervision of the Federal Inspection Service.

The strains used were previously isolated and characterized by Melo (2017), following the ISO isolation protocols (International Standards Organization, 2006). Species identification was performed by multiplex PCR according to the protocol defined by Harmon et al. (1997), followed by maintenance at $-80^{\circ} \mathrm{C}$ and reactivation, according to ISO (2006).

\section{Phylogenetic Analysis}

The genetic similarity between the isolates was determined by the RAPD-PCR (random amplification of polymorphic DNA) technique in order to prove the phylogenetic distinction between the strains. We performed the analysis in three repetitions or until we obtained three identical results in order to guarantee the selection of more reliable data. The analysis was not possible in five of the 35 strains since the amplicons of DNA were not obtained for all strains using the selected primers, or it was not possible to obtain identical results for these strains.

Genomic DNA was extracted using the Genomic DNA Purification Wizard Kit (Promega, Madison, Wisconsin, USA), following the protocol established by the manufacturer. Purified DNA (10 ng) was used for the RAPD-PCR, which were performed with the HLWL85 (5'ACGTATCTGC3') and 1290 (5'GTGGATGCGA3') primers (Akopyanz et al., 1992; Mazurier et al., 1992). The RAPD-PCR technique was performed according to Akopyanz et al. (1992) until three repetitions were obtained with identical results for the same strain. The reaction was prepared in a total volume of $20 \mu \mathrm{L}$, composed of 10 $\mathrm{ng} / \mu \mathrm{l}$ of bacterial DNA, $10 \mathrm{mM}$ of Tris-HCL; $50 \mathrm{mM}$ of $\mathrm{KCl} ; 2.0$ $\mathrm{mM}$ of $\mathrm{MgCl}_{2}$ and $1 \mathrm{U}$ of Taq DNA polymerase (Invitrogen ${ }^{\circledR}$, Waltham, Massachusetts, USA); $200 \mu \mathrm{M}$ of each triphosphate deoxynucleotide (DNTP) (Invitrogen ${ }^{\circledR}$, Waltham, Massachusetts, USA) and 30 picomoles of the primer (Invitrogen ${ }^{\circledR}$, Waltham, Massachusetts, USA).

The amplification occurred under the following conditions: 1 initial denaturation cycle at $92^{\circ} \mathrm{C}$ for 2 minutes; 35 cycles of three stages: denaturation at $92{ }^{\circ} \mathrm{C}$ for 15 seconds, annealing at $36^{\circ} \mathrm{C}$ for 1 minute, extension at $72^{\circ} \mathrm{C}$ for 1 minute; and one final extension cycle at $72^{\circ} \mathrm{C}$ for 5 minutes.

The amplified products were submitted to electrophoresis on $1.5 \%$ agarose gel (Affymetrix ${ }^{\circledR}$, Santa Clara, California, USA), using TBE 0.5X running buffer (Invitrogen ${ }^{\circledR}$, Waltham, Massachusetts, USA) and the $100 \mathrm{bp}$ marker (Invitrogen ${ }^{\circledR}$, Waltham, Massachusetts, USA) as the molecular weight standard. The gel was stained with Syber Safe (Invitrogen ${ }^{\circledR}$, Waltham, Massachusetts, USA), visualized and captured in a transilluminator (Loccus Biotecnologia, Cotia, São Paulo, Brazil).

The dendrogram was built using the GelCompar II software (Comparative Analysis of Electrophoresis Patterns), version 1.50. The comparison of the band patterns was performed by the UPGMA method (unweighted pair group method with arithmetic mean), using the Dice similarity coefficient. Strains considered similar were only those that showed 95\% of homology due to the discriminatory power of the technique. 


\section{Planktonic Cells}

After the reactivation of strains on CCDA agar (Campylobacter Blood-Free Selective Agar Base) (Oxoid, Basingstock, Hampshire, $\mathrm{UK}$ ), isolated colonies were introduced in $2 \mathrm{~mL}$ of $85 \% \mathrm{NaCl}$ $\left(\right.$ Synth $^{\circledR}$, Diadema, São Paulo, Brazil) and the standardized concentration was 0.5 on the McFarland scale, corresponding at $5.5 \log \mathrm{CFU} / \mathrm{mL}$ (EUCAST, 2020) to determine the antibiotic susceptibility testing (Antibiotic Susceptibility Testing).

\section{Biofilm Formation (Traditional Method)}

For the biofilm formation, initially, the cultures present in the CCDA plates were transferred to $20 \mathrm{~mL}$ of Mueller Hinton broth (MH) (Difco, Sparks, Maryland, USA) supplemented with 5\% of $\mathrm{CJ}$ and incubated at $37^{\circ} \mathrm{C}$ for 48 hours under microaerophilia. To simulate the nutritional conditions of abiotic surfaces present during processing in poultry industry and to guarantee qualitative and quantitative stability of the biofilm (Melo et al., 2017), we used the model system with 5\% CJ, equivalent to $100 \%$ concentration according to Brown et al. (2014), based on supplementation of the culture medium with thawed poultry exudates sterilized by filtration (Birk et al., 2006).

After growth, the bacterial suspension was standardized to an $\mathrm{OD}_{600}=0.22$ to 0.28 and centrifuged at $5000 \mathrm{rpm}$ for $10 \mathrm{~min}$ at $4^{\circ} \mathrm{C}$. After discarding the supernatant, the cells were washed and centrifuged twice in $0.9 \%$ sterile $\mathrm{NaCl}$ solution. The supernatant was discarded, and the pellet was resuspended in $0.9 \% \mathrm{NaCl}$ solution and diluted in $10 \mathrm{~mL}$ of supplemented $\mathrm{MH}$ broth in order to obtain a final count of $10^{4} \mathrm{CFU} / \mathrm{mL}$.

The technique of biofilm formation was performed according to Sulaeman et al. (2009), with modifications. Briefly, $200 \mu \mathrm{L}$ of the bacterial suspension in $\mathrm{MH}$ with $5 \%$ of CJ containing $10^{4}$ cells was added in 96-well plates and incubated for 48 hours at $37^{\circ} \mathrm{C}$ under microaerophilic conditions. Afterwards, the nonadherent bacteria were washed twice with $0.9 \%$ sterile $\mathrm{NaCl}$ solution and the biofilm formed, corresponding to an average of $6.14 \pm 0.52 \log \mathrm{CFU} / \mathrm{mL}$, was maintained for treatment with antibiotics, as described in Antibiotic Susceptibility Testing.

\section{Antibiotic Susceptibility Testing}

After preparing the suspension of free bacteria (Planktonic Cells) and the production of biofilms in the microplates [Biofilm Formation (Traditional Method)], the antimicrobial susceptibility of 35 strains in planktonic and biofilm forms was determined against ciprofloxacin (fluoroquinolone that acts on bacterial DNA replication), erythromycin (macrolide that inhibits protein synthesis and translation), tetracycline (tetracycline inhibiting protein synthesis), meropenem (carbapenem that inhibits cell wall synthesis) and colistin (polymyxin that acts in the destructuring bacterial cell membrane) (Abushaheen et al., 2020), the latter being little studied due to considering resistance as intrinsic to the pathogen. The method used was the broth microdilution in microplates (Kasvi, São Jose dos Pinhais, Brazil), as described in EUCAST (2020), following the specifications and cutoff points for Campylobacter and Enterobacteriaceae, when applicable.

The criterion for choosing these antimicrobials was based on the use of this drug in veterinary and human medicine and because of their different mechanisms of action. The tested concentrations were: $0.125,0.25,0.5,1,2,4,8,16,32,64,128$, and $256 \mu \mathrm{g} . \mathrm{mL}^{-1}$.

For the planktonic form, twenty microliters of the bacterial suspension were transferred into $180 \mu \mathrm{L}$ cation-adjusted (20-25 $\mathrm{mg} / \mathrm{L} \mathrm{Ca}^{2+}, 10-12.5 \mathrm{mg} / \mathrm{L} \mathrm{Mg}^{2+}$ ) $\mathrm{MH}$ with antimicrobial and 5\% lysed sheep blood (LaborClin, Pinhais, Paraná, BR). For biofilms already present in microplates, we only transferred $200 \mu \mathrm{L}$ cation-adjusted (20-25 mg/L Ca $\left.{ }^{2+}, 10-12.5 \mathrm{mg} / \mathrm{L} \mathrm{Mg}^{2+}\right) \mathrm{MH}$ with antimicrobial and 5\% lysed sheep blood (LaborClin, Pinhais, Paraná, BR). The multiwell plate was sealed and incubated at $41 \pm 1^{\circ} \mathrm{C}$ for $40-48 \mathrm{~h}$ in microaerobic conditions. In addition, a $10 \mu \mathrm{L}$ aliquot of each diluted inoculum was plated in CCDA agar (Oxoid, Basingstock, Hampshire, UK) to check the bacterial growth (viability) of the respective dilution well.

For all tests, negative controls composed of the medium without the addition of bacteria were used. For the tests performed for colistin, E. coli ATCC 25922 and E. coli NCTC 13846 strains were used as positive controls, the latter being positive for the morl gene, as recommended in the EUCAST manual (2020), and for the other determinations, the strains $C$. jejuni IAL 2383 and NCTC 11351 were used as positive controls.

\section{Biomass Analysis}

Qualitative analysis of biofilm biomass with (tests) and without (control) antimicrobial treatment at a concentration of 32 $\mu \mathrm{g} . \mathrm{mL}^{-1}$ was performed on two strains of C. jejuni, previously characterized in terms of the resistance profile in this study (F048 and F639). The strains were selected considering their differences linked from origin industry, isolation years (2015 and 2016, respectively), phylogenetic distance (53\% of similarity - Figure 1) and previous antimicrobial susceptibility testing results in planktonic form (the first susceptible to tetracycline and erythromycin and the second pan-resistant - Table 1) and sessile form (F048 susceptible to tetracycline and F639 panresistant - Table 1). This method was adopted to verify the variation of biomass (sessile bacteria + extracellular matrix) in biofilms produced by $C$. jejuni without and with antibiotic treatment. The concentration of antibiotic used was defined based on preliminary results that demonstrated MIC $\geq 32 \mu \mathrm{g} \cdot \mathrm{mL}^{-1}$ for all tested antibiotics, except tetracycline, being one strain susceptible and the other resistant to tetracycline in biofilm form (Table 2 ).

The biofilms produced in multiwell plates, according to Biofilm Formation (Traditional Method), were treated with five classes of antimicrobials at a concentration of $32 \mu \mathrm{g} \cdot \mathrm{mL}^{-1}$ prepared in cation-adjusted $\left(20-25 \mathrm{mg} / \mathrm{L} \mathrm{Ca}^{2+}, 10-12.5 \mathrm{mg} / \mathrm{L}\right.$ $\mathrm{Mg}^{2+}$ ) $\mathrm{MH}$ with 5\% lysed sheep blood (LaborClin, Pinhais, Paraná, BR). For control, we use only cation-adjusted (20-25 $\mathrm{mg} / \mathrm{L} \mathrm{Ca}^{2+}, 10-12.5 \mathrm{mg} / \mathrm{L} \mathrm{Mg}^{2+}$ ) MH with $5 \%$ lysed sheep blood (LaborClin, Pinhais, Paraná, BR) without antimicrobial. The multiwell plates were incubated as described in EUCAST (2020).

After obtaining and treating of the biofilms, the media was removed, the wells were washed twice with $0.9 \% \mathrm{NaCl}$ solution and dried for 30 minutes at $55^{\circ} \mathrm{C}$. The total biomass was measured by fixing with $0.1 \%$ Violet Crystal (LaborClin, 


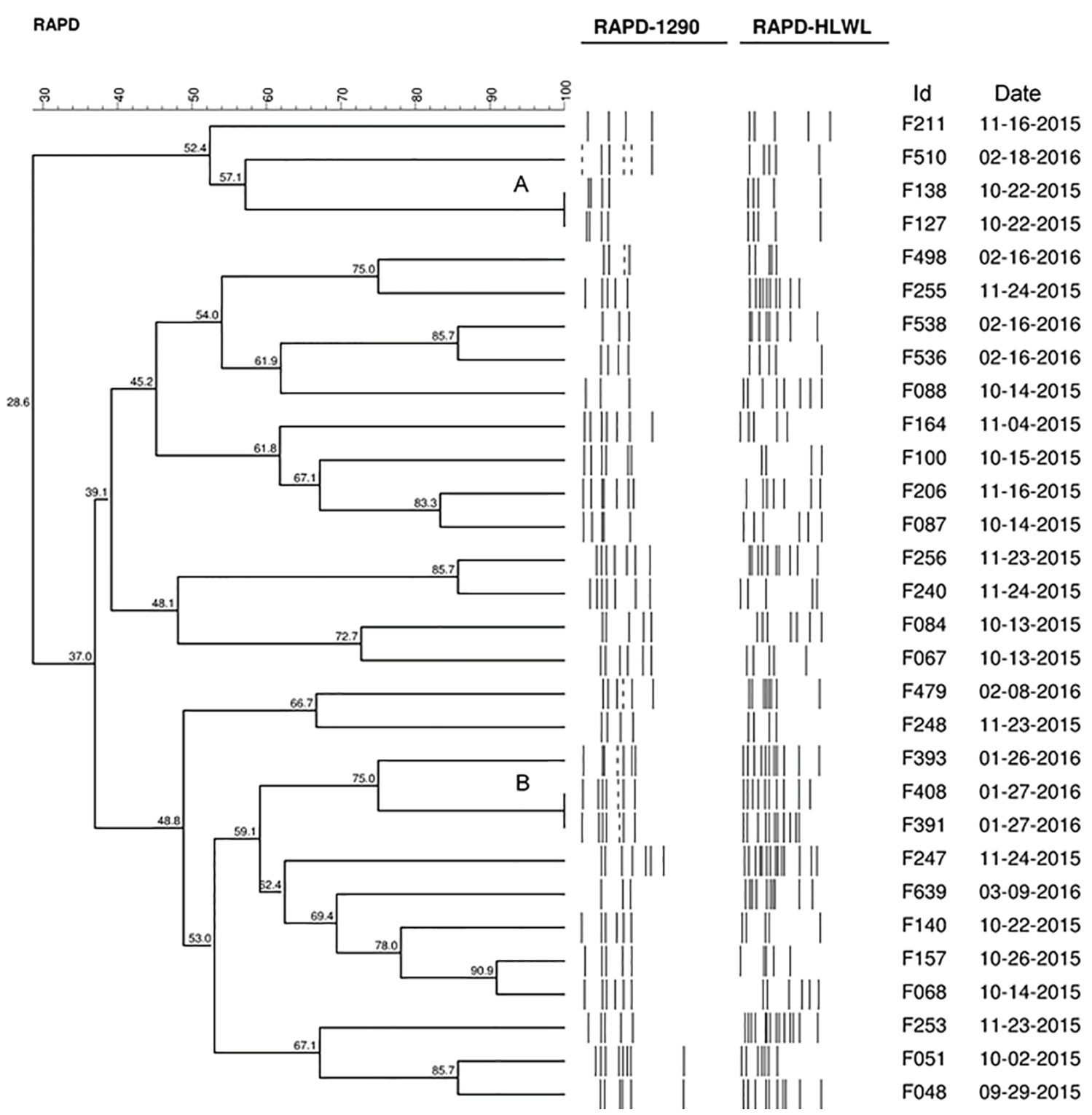

FIGURE 1 | Dendrogram generated by computerized analysis (Gel Compare II) of DNA profiles of 30 strains of C. jejuni, based on RAPD-PCR. The analysis was performed using the Dice/UPGMA method (0.5\% tolerance parameter, $0.5 \%$ optimization, homology $\geq 95 \%$ ).

Pinhais, Paraná, BR) for 5 minutes, followed by elution with methanol solution $\left(\right.$ Synth ${ }^{\circledR}$ ). The eluted dye was evaluated by reading at the $\mathrm{OD}_{595}$. The tests were performed with eight replicates for each strain in three replications.

To determine the Biofilm Formation Index, the following formula was used: $\mathrm{BFI}=(\mathrm{BA}-\mathrm{PC}) / \mathrm{BS}$, where BFI represents the result referring to the Biofilm Formation Index, BA the optical density obtained in the mixture of adhered bacteria, PC the value of the absorbance in microorganism-free control wells, BS the optical density of cultures in suspension (Naves et al., 2008). For the BFI classification were considered, $\geq 1.10=$ strong, $0.70-1.10=$ medium, $0.35-0.69=$ weak, and $<0.35=$ non-existent.

\section{Biomass Analysis in Different Materials}

For the biofilm production by the two selected strains (F048 and F639), the tests were performed in triplicate in three independent periods. The tests were performed on $1 \mathrm{~cm}^{2}$ slides of the following materials: polyurethane (PU) (Habasit Cleandrive TM, Reinach, $\mathrm{CH}$ ), polypropylene (PP) (Leadmec, Belo Horizonte, Minas Gerais, BR), and stainless steel (AISI 304).

The initial inoculum for biofilm production was $6.66 \pm 0.28$ $\log \mathrm{CFU} / \mathrm{mL}$, corresponding to DO600nm of 0.22 to 0.28 , obtained in bacterial suspension in $\mathrm{MH}$ broth with $5 \%$ of $\mathrm{CJ}$. The inoculum was then used to produce biofilms on slides 48 hours at $37^{\circ} \mathrm{C}$ under microaerophilic conditions. Three slides of 
TABLE 1 | MIC of biofilm and planktonic forms of two strains of $C$. jejuni used in biomass and imaging tests.

\begin{tabular}{|c|c|c|c|c|}
\hline \multirow{2}{*}{$\begin{array}{l}\text { Strains } \\
\text { F048 }\end{array}$} & \multicolumn{2}{|c|}{$\begin{array}{l}\text { MIC in planktonic form } \\
\text { Antimicrobial (mg/L) S/R }\end{array}$} & \multicolumn{2}{|c|}{$\begin{array}{c}\text { MIC in biofilm form } \\
\text { Antimicrobial (mg/L) S/R }\end{array}$} \\
\hline & $\begin{array}{l}\text { CIP (4) R } \\
\text { TET }(<0.125) S \\
\text { MER (1) S }\end{array}$ & $\begin{array}{l}\text { COL (16) R } \\
\text { ERY (2) S }\end{array}$ & $\begin{array}{l}\text { CIP }(>256) R \\
\text { TET (2) S } \\
\text { MER (>256) R }\end{array}$ & $\begin{array}{l}\text { COL (256) R } \\
\text { ERY (256) R }\end{array}$ \\
\hline F639 & $\begin{array}{l}\text { CIP (64) R } \\
\text { TET (128) R } \\
\text { MER (64) R }\end{array}$ & $\begin{array}{l}\text { COL (256) R } \\
\text { ERY (64) R }\end{array}$ & $\begin{array}{l}\text { CIP }(256) R \\
\text { TET }(>256) R \\
\text { MER }(>256) R\end{array}$ & $\begin{array}{l}\mathrm{COL}(>256) \mathrm{R} \\
\mathrm{ERY}(>256) \mathrm{R}\end{array}$ \\
\hline
\end{tabular}

each material (for each strain and for each antimicrobial) were aseptically transferred to a 24-well polystyrene plate (Kasvi, São José dos Pinhais, Paraná, BR) in each repetition. After biofilm formation, we determined the effect of the five antimicrobials on the biofilms produced. The slides were aseptically transferred to 24-wells polystyrene plates (Kasvi, São José dos Pinhais, Paraná, $\mathrm{BR}$ ) and treated with five classes of antimicrobials at a concentration of $32 \mu \mathrm{g} . \mathrm{mL}-1$ prepared in cation-adjusted (20$25 \mathrm{mg} / \mathrm{L} \mathrm{Ca}^{2+}, 10-12.5 \mathrm{mg} / \mathrm{L} \mathrm{Mg}^{2+}$ ) MH with $5 \%$ lysed sheep blood (LaborClin, Pinhais, Paraná, BR). For control, we use only cation-adjusted (20-25 mg/L Ca ${ }^{2+}, 10-12.5 \mathrm{mg} / \mathrm{L} \mathrm{Mg}^{2+}$ ) $\mathrm{MH}$ with $5 \%$ lysed sheep blood (LaborClin, Pinhais, Paraná, BR) without antimicrobial. The 24 -wells polystyrene plates were incubated as described in EUCAST (2020).

After incubation, these slides were washed twice with $0.9 \%$ $\mathrm{NaCl}$ solution, transferred to a new 24 -well polystyrene plate, and dried for 30 minutes at $55^{\circ} \mathrm{C}$. The total biomass was measured by fixing with $0.1 \%$ Violet Crystal (LaborClin, Pinhais, Paraná, BR) for 5 minutes, followed by elution with methanol solution $\left(\right.$ Synth $\left.^{\circledR}\right)$. The dissolved dye was removed from each slide and placed in a new 96-wells microtiter plate for $\mathrm{OD}_{595}$ reading on a spectrophotometer (DNM-9602 microplate reader Perlong). The biomass classification of biofilms was performed according to the protocol described by (Naves et al., 2008), described in Biomass Analysis.

\section{Scanning Microscopy}

The visualization of the biomass formed with (tests) and without (control) antimicrobial treatments at a concentration of 32 $\mu \mathrm{g} . \mathrm{mL}^{-1}$ was performed in a scanning electron microscope, with two strains of $C$. jejuni, one susceptible and the other resistant to tetracycline in a biofilm form (F048 and F639). The preparation of the material for analysis in the SEM was done according to Brown et al. (2014), with modifications. Biofilms were formed in glass beads with a diameter of $5 \mathrm{~mm}$, respecting the growth conditions described above. After biomass formation, the samples were fixed with $2.5 \%$ glutaraldehyde and $2.5 \%$ paraformaldehyde in $0.1 \mathrm{M}$ PBS buffer $(\mathrm{pH} 7.4$ ) overnight at $4^{\circ} \mathrm{C}$. The fixative was removed, and the samples were washed three times with PBS buffer. The beads were post-fixed with $1 \%$ osmium tetroxide for two hours and washed three times with PBS buffer. The beads were dehydrated in a series of ethanol solutions $(30,40,50,60,70,80$, and $90 \%$ and then three times at $100 \%)$ for 15 minutes for each step.

The samples were dried on CDP (critical drying point) (CDP 030, Baltec, DE) using liquid carbon dioxide as the transition fluid, then coated with a 20nm thick gold layer (SCD 050, Baltec, DE) and visualized in SEM VP Zeiss Supra 55 FEG SEM operating at $20 \mathrm{kV}$.

\section{Statistical Analysis}

The test results were submitted to descriptive statistics, normality analysis, followed by application of the $\mathrm{T}$ student test/MannWhitney test (for comparisons of results referring to concentrations necessary for the control biofilms), Fisher's exact test (used in results comparisons obtained for planktonic and biofilms forms), ANOVA/Kruskal-Wallis (in the interpretation of data obtained in biomass tests). A significance level of 5\% was adopted, using the Graph Pad Prism 8.0.1 Program for the calculations.

\section{RESULTS}

\section{Genetic Proximity}

Using 95\% of similarity values, RAPD-PCR revealed significant differences in the 30 strains of $C$. jejuni population evaluated and, therefore, they were considered different strains. The exception was for two clusters with $100 \%$ of similarity (A and B) detected in the dendrogram produced by the analysis of the 30 strains (Figure 1). Cluster A included strains F127 and F138 resistant to ciprofloxacin, colistin, and tetracycline, and cluster B included strains resistant to ciprofloxacin and tetracycline (F391 and F408). In addition, in biofilms, all these strains showed resistance to all the studied drugs.

\section{Resistance of Planktonic C. jejuni}

Our study found resistance percentages $\geq 80 \%$ for ciprofloxacin ( $31 /$ $35,88.6 \%)$, tetracycline $(30 / 35,85.7 \%)$, and colistin $(28 / 35,80.0 \%)$ in planktonic form. The highest susceptibility was attributed to meropenem $(32 / 35,91.4 \%)$ and erythromycin $(23 / 35,65.7 \%)$, therefore, considered the most efficient drugs (Table 2).

Low concentrations were sufficient for $\mathrm{MIC}_{50}$ of meropenem $(0.25 \mathrm{mg} / \mathrm{L})$ and erythromycin $(0.5 \mathrm{mg} / \mathrm{L})$, whereas for tetracycline, ciprofloxacin, and colistin the values were 32,128 , and $256 \mathrm{mg} / \mathrm{mL}$, respectively. $\mathrm{MIC}_{90}$ was 8 and $256 \mathrm{mg} / \mathrm{L}$ for meropenem and erythromycin, respectively; for the other antibiotics, the concentration was higher than $256 \mathrm{mg} / \mathrm{L}$ (Table 2).

We identified 11 resistance profiles, $14.3 \%$ (5/35) of whom presented co-resistance. Multiple antimicrobial resistance (MDR) (resistance to three or more classes of antimicrobials) was presented 
TABLE 2 | MIC, MIC $50, \mathrm{MIC}_{90}$, and resistance rate distributions for investigated of $35 \mathrm{C}$. jejuni strains in biofilm and planktonic forms.

\begin{tabular}{|c|c|c|c|c|c|c|c|c|c|c|}
\hline Antibiotics (mg/L) & CIPPL & CIPBF & COLPL & COLBF & TETPL & TETBF & ERYPL & ERYBF & MERPL & MERBF \\
\hline$<0.125$ & 01 & - & - & - & 04 & - & 08 & - & 10 & - \\
\hline 0.125 & 01 & - & - & - & - & - & - & - & 05 & - \\
\hline 0.25 & 02 & - & 02 & - & 01 & - & 04 & - & 05 & - \\
\hline 0.5 & - & - & 03 & - & - & - & 06 & - & 01 & - \\
\hline 1 & 01 & - & 02 & - & - & 02 & 01 & - & 02 & - \\
\hline 2 & 01 & - & - & - & - & 01 & 02 & - & 03 & - \\
\hline 4 & 03 & - & 01 & - & 03 & 01 & 02 & - & 03 & - \\
\hline 8 & 01 & - & - & - & 01 & 02 & - & - & 03 & - \\
\hline 16 & 02 & - & 01 & - & 06 & 02 & 02 & - & - & - \\
\hline 32 & 03 & - & 04 & 01 & 06 & 02 & 01 & 01 & 02 & - \\
\hline 64 & 02 & - & - & 02 & 07 & 03 & 02 & - & 01 & - \\
\hline 128 & 02 & 03 & 03 & 03 & 01 & 08 & 03 & - & - & 02 \\
\hline 256 & 06 & 11 & 02 & 04 & 01 & 03 & 04 & 07 & - & 06 \\
\hline$>256$ & 10 & 21 & 17 & 25 & 05 & 11 & - & 27 & - & 27 \\
\hline $\begin{array}{l}\text { Total Resistant } \\
\mathrm{n}(\%) \\
\end{array}$ & $\begin{array}{c}31 \\
(88.6) \\
\end{array}$ & $\begin{array}{c}35 \\
(100)\end{array}$ & $\begin{array}{l}28^{*} \\
(80)\end{array}$ & $\begin{array}{c}35^{\star} \\
(100)\end{array}$ & $\begin{array}{c}30 \\
(85.7) \\
\end{array}$ & $\begin{array}{c}32 \\
(91.4) \\
\end{array}$ & $\begin{array}{l}12^{\star \star} \\
(34.3)\end{array}$ & $\begin{array}{l}35^{\star \star} \\
(100)\end{array}$ & $\begin{array}{l}03^{\star \star} \\
(8.6)\end{array}$ & $\begin{array}{l}35^{\star \star} \\
(100)\end{array}$ \\
\hline $\begin{array}{l}\text { Total Resistant } \geq 32 \\
-\mathrm{n}(\%)\end{array}$ & $\begin{array}{c}23^{\star} \\
(65.7) \\
\end{array}$ & $\begin{array}{c}35^{\star} \\
(100)\end{array}$ & $\begin{array}{c}26^{*} \\
(74.3)\end{array}$ & $\begin{array}{c}35^{\star} \\
(100) \\
\end{array}$ & $\begin{array}{c}20 \\
(57.1)\end{array}$ & $\begin{array}{c}27 \\
(77.1) \\
\end{array}$ & $\begin{array}{c}10^{\star \star} \\
(28.6)\end{array}$ & $\begin{array}{l}35^{\star \star} \\
(100)\end{array}$ & $\begin{array}{l}03^{\star \star} \\
(8.6)\end{array}$ & $\begin{array}{l}35^{\star \star} \\
(100)\end{array}$ \\
\hline $\mathrm{MIC}_{50}$ & 128 & $>256$ & 256 & $>256$ & 32 & 128 & 0.5 & $>256$ & 0.25 & $>256$ \\
\hline $\mathrm{MIC}_{90}$ & $>256$ & $>256$ & $>256$ & $>256$ & $>256$ & $>256$ & 256 & $>256$ & 8 & $>256$ \\
\hline
\end{tabular}

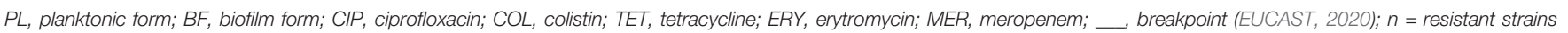
number; $\%=$ Resistance rate; ${ }^{*} p<0.05,{ }^{* *} p<0.0001$ using Fisher's exact test.

in $71.4 \%(25 / 35)$ and included six distinct profiles, two (P6 and P7) grouping 12 strains resistant to three classes, two (P8 and P9) with 12 other strains resistant to four classes and one profile (P11) with a strain resistant to all tested classes. The most frequent profile was P6, which included 11 of the 35 strains (31.4\%) and indicated joint resistance to ciprofloxacin, colistin, and tetracycline, followed by P8 with $28.6 \%(10 / 35)$ of strains resistant to the same antibiotics and also erythromycin. If we consider the intrinsic resistance to colistin, the total of multiresistant strains was 13/35 (37.1\%) (Table 3).

TABLE 3 | Resistance profiles in 35 Campylobacter jejuni isolated from poultry meat.

\begin{tabular}{lcc}
\hline Antimicrobial agents & Planktonic $\mathbf{N}(\%)$ & Biofilm $\mathbf{~ ( \% ) ~}$ \\
\hline (P1) CIP & 1 & - \\
(P2) COL & 2 & - \\
(P3) TET & 2 & - \\
Total mono-resistant isolates & $\mathbf{5 ( 1 4 . 3 )}$ & $\mathbf{0}$ \\
(P4) CIP-TET & 4 & - \\
(P5) CIP-COL & 1 & - \\
Total co-resistant isolates & $\mathbf{5 ( 1 4 . 3 )}$ & $\mathbf{0}$ \\
(P6) CIP-COL-TET & 11 & - \\
(P7) CIP-COL-ERY & 1 & - \\
(P8) CIP-COL-TET-ERY & 10 & - \\
(P9) CIP-COL-TET-MER & 2 & - \\
(P10) CIP-COL-ERY-MER & - & 3 \\
(P11) CIP-COL-TET-ERY-MER & 1 & 32 \\
Total MDR isolates & $\mathbf{2 5}(\mathbf{7 1 . 4})^{\mathbf{a}}$ & $\mathbf{3 5}(\mathbf{1 0 0 . 0})^{\mathbf{b}}$ \\
\hline
\end{tabular}

CIP, ciprofloxacin; COL, colistin; TET, tetracycline; ERY, erytromycin; MER, meropenem; N (\%), total number and percent of $C$. jejuni isolates; $P$, profile; Superscript letter ${ }^{(a)}$ or b), distinct letters in the same row indicate that numbers are statistically different (Fisher's exact test). The final value referring to the previous lines and the option in bold highlights the information.

\section{Resistance of C. jejuni Biofims}

In general, our results showed that the tested drugs had no effect on the biofilm structure of C. jejuni. Only for tetracycline was it possible to detect some exceptions.

The sessile cells in biofilms of the 35 strains of $C$. jejuni were resistant to ciprofloxacin, erythromycin, colistin, and meropenem, requiring concentrations equal to or greater than $32 \mathrm{mg} / \mathrm{L}$ to inhibit them. The exception is tetracycline, in which three strains $(8.6 \%)$ were susceptible according to the breakpoint defined by EUCAST (2020). All strains (100\%) in biofilms were resistant to erythromycin, meropenem, and colistin, showing that there was a significant increase compared to the number of resistant strains in planktonic form $(12 / 35 ; 3 / 35$; and $28 / 35$, respectively). When the analysis was restricted to concentrations $\geq 32 \mathrm{mg} / \mathrm{L}$ of the antibiotic, only for tetracycline we did not observe a difference in both forms of life (20 plactonic strains and 27 sessile strains) (Table 1). In addition, for tetracycline alone, we detected an average of 19 -fold reduction in MIC value in four strains (11.4\%) in biofilms.

The $\mathrm{MIC}_{50}$ and $\mathrm{MIC}_{90}$ of tetracycline were 128 and $>256 \mathrm{mg} /$ $\mathrm{L}$, respectively. For the other antimicrobials, this value was $>256$ $\mathrm{mg} / \mathrm{L}$ for both $\mathrm{MIC}_{50}$ and $\mathrm{MIC}_{90}$ (Table 2).

The need for high concentrations of antimicrobials to control sessile cells of $C$. jejuni in biofilms showed the highest number of multidrug-resistant strains, found in all strains in profiles P10 (CIP-COL-ERY-MER) detected in 3/35 (8.6\%) strains and P11 (all classes) in 32/35 (91.4\%) strains (Table 3).

We consider concentrations $>256$ and $<0.125 \mathrm{mg} / \mathrm{L}$ equal to the values immediately above and below, 512 and $0.0625 \mathrm{mg} / \mathrm{L}$, respectively, to allow the quantitative analysis of all strains. The 
variation in the concentration of antibiotic needed to inhibit the sessile cells in biofilm was strain-dependent for all tested antibiotics, and this characteristic was maintained when separately evaluating susceptible and resistant strains $(\mathrm{p}<0.05)$. Susceptible strains needed an average concentration of 2,595 \pm 353.4 times higher of antibiotics to inhibit sessile cells compared to planktonic bacteria, with no significant difference between the drugs tested ( $\mathrm{p}=0.0956$ ). This value was significantly lower for resistant bacteria and equivalent to $12.6 \pm 3.3$ and statistically equal for all antibiotics (Table 4).

In the evaluation of all strains, we observed that there was no difference in the average increase in the concentrations of ciprofloxacin, colistin, and tetracycline necessary to inhibit sessile cells (Table 4), probably because we had a greater number of resistant strains for these antibiotics (Table 2). Similarly, for erythromycin and meropenem, as we had a greater number of susceptible strains. In an analysis that includes only the precise values obtained in the MIC, with the concentration range evaluated $(0.125,0.25,0.5,1,2,4$, $8,16,32,64,128$, and $256 \mathrm{mg} / \mathrm{L}$ ), we detected that susceptible strains needed an average concentration of $376.3 \pm$ 240.2 times higher of antibiotics, regardless of class ( $\mathrm{p}=$ 0.4414), to control the sessile cells in biofilm form. Resistant strains, on the other hand, needed an average concentration $24.74 \pm 26.53(\mathrm{p}=0.4475)$ times higher, a value significantly lower than that observed for susceptible bacteria $(\mathrm{p}=0.0285$, t-Test).

\section{Analysis of Biomass of C. jejuni Biofilms}

Biomass tests, as well as imaging tests, were performed only with strains F048 and F639. The characterization of the antimicrobial resistance profile for these two strains is described in Table $\mathbf{1 .}$

Both strains were classified as strong producers of biofilms in the BFI in the control group in the microplate test and for the three different surfaces tested $(1.303 \pm 0.025)$ (Figure 2). After treatment with ciprofloxacin, colistin, erythromycin, and meropenem, we observed a significant mean increase of $0.877,1.162,0.585$ and 0.654 in the biomass intensity in the traditional test and on stainless steel, polypropylene and polyurethane surfaces, respectively. In contrast, treatment with tetracycline reduced the biofilm classification to low intensity in strain F048 and medium intensity to F639, in the traditional method (mean $=-0.751$ ), and for low intensity in both strains on the three surfaces (mean $=-0.893$ ).

For the traditional method, we observed that the sensitivity of F048 to erythromycin and meropenem detected in the planktonic form promoted a greater stimulus in the production of biomass when compared with F639 (pan-resistant strain) (mean $=+0.27$ and +0.41 , respectively) (Figure 2A). This same profile was maintained in the biofilms produced on the different surfaces exposed to meropenem (mean $=+1.10,+0.42$, and +0.58 , respectively to stainless steel, polypropylene and polyurethane) (Figures 2 B-D).

In a different way, tetracycline promoted a significant reduction in the F048 biomass (susceptible in planktonic and biofilm forms) compared to F638, for traditional analysis (mean $=-0.51)$. The same behavior observed in biofilms treated with ciprofloxacin and colistin was expected since both strains were resistant to these drugs (Figure 2A). On the different surfaces tested, we detected significant fluctuations in the biomass produced in contact with the antimicrobials, consistent with a strain-dependent character. The exception is tetracycline, whose BFI profile has not changed according to the type of surface (0.36 to 0.51 = weak BFI) (Figures 2B-D).

The heat map made it evident that stainless steel intensified the production of biomass treated with ciprofloxacin $(\mathrm{BFI}=$ $2.841)$, colistin $(\mathrm{BFI}=2.486)$ and erythromycin $(\mathrm{BFI}=2.686)$. Polyurethane was the least favorable surface for biofilms treated with tetracycline $(\mathrm{BFI}=0.333)$ and meropenem $(\mathrm{BFI}=1.735)$, as well as polypropylene in biofilms in contact with erythromycin $(\mathrm{BFI}=1.767)($ Figure 3$)$.

\section{Image Analysis of C. jejuni Biofilms}

In the SEM of strains F048 and F639, we observed the formation of mature biofilms with an evident three-dimensional structure of the matrix, however, three distinct characteristics were detected. The first one concerned an expanded architecture, compact matrix, large pores, and bacteria exposed on the surface (control). In the second morphology, we found a layered arrangement showing an increase in the three-dimensional structure, compact matrix, pores of smaller size, and absence of exposed bacteria in the superficial portion (treatments with ciprofloxacin, colistin, erythromycin, and meropenem). The last case concerned a biofilm in the death or disintegration phase, with matrix destruction, absence of pores, bacterial exposure, and evidence of cell death (treatment with tetracycline) (Figure 4).

\section{DISCUSSION}

\section{Genetic Diversity}

The genetic diversity of 30 from 35 strains of C. jejuni was assessed using RAPD-PCR. Although RAPD-PCR is not the gold standard for genotyping due to low reproducibility, it is a cheap, easy, and discriminatory typing method to investigate the genome variability of a large isolates number, particularly for

TABLE 4 | The average increase in antimicrobial concentrations necessary for the inhibition of biofilms in 35 strains of $C$. jejuni compared to MIC in planktonic form.

\begin{tabular}{|c|c|c|c|c|c|c|}
\hline Antimicrobial & CIP & COL & TET & ERY & MER & General average \\
\hline All strains & $314.4 \pm 234.3^{A}$ & $96.5 \pm 59.1^{\mathrm{A}}$ & $71.1 \pm 58.4^{\mathrm{A}}$ & $1,826 \pm 450.3^{\mathrm{B}}$ & $2,994 \pm 542 \cdot 1^{\mathrm{B}}$ & $1,060 \pm 172.1$ \\
\hline Susceptible & $2,560 \pm 1,881^{\mathrm{Aa}}$ & $466.3 \pm 265.2^{\mathrm{Aa}}$ & $448 \pm 400.5^{\mathrm{Aa}}$ & $2,772 \pm 598.5^{\mathrm{Aa}}$ & $3,274 \pm 568.5^{\mathrm{Aa}}$ & $2,595 \pm 353.4^{\mathrm{Aa}}$ \\
\hline Resistant & $24.7 \pm 9.8^{\mathrm{Ab}}$ & $4 \pm 1.4^{\mathrm{Ab}}$ & $8.6 \pm 4.7^{\mathrm{Ab}}$ & $11.7 \pm 3.7^{\mathrm{Ab}}$ & $13.3 \pm 2.7^{\mathrm{Ab}}$ & $12.6 \pm 3.3^{A b}$ \\
\hline
\end{tabular}

CIP, ciprofloxacin; COL, colistin; TET, tetracycline; ERY, erythromycin; MER, meropenem; Different uppercase letters on the lines indicate a significant difference, different lowercase letters on the columns indicate a significant difference (Kruskal-Wallis test). 


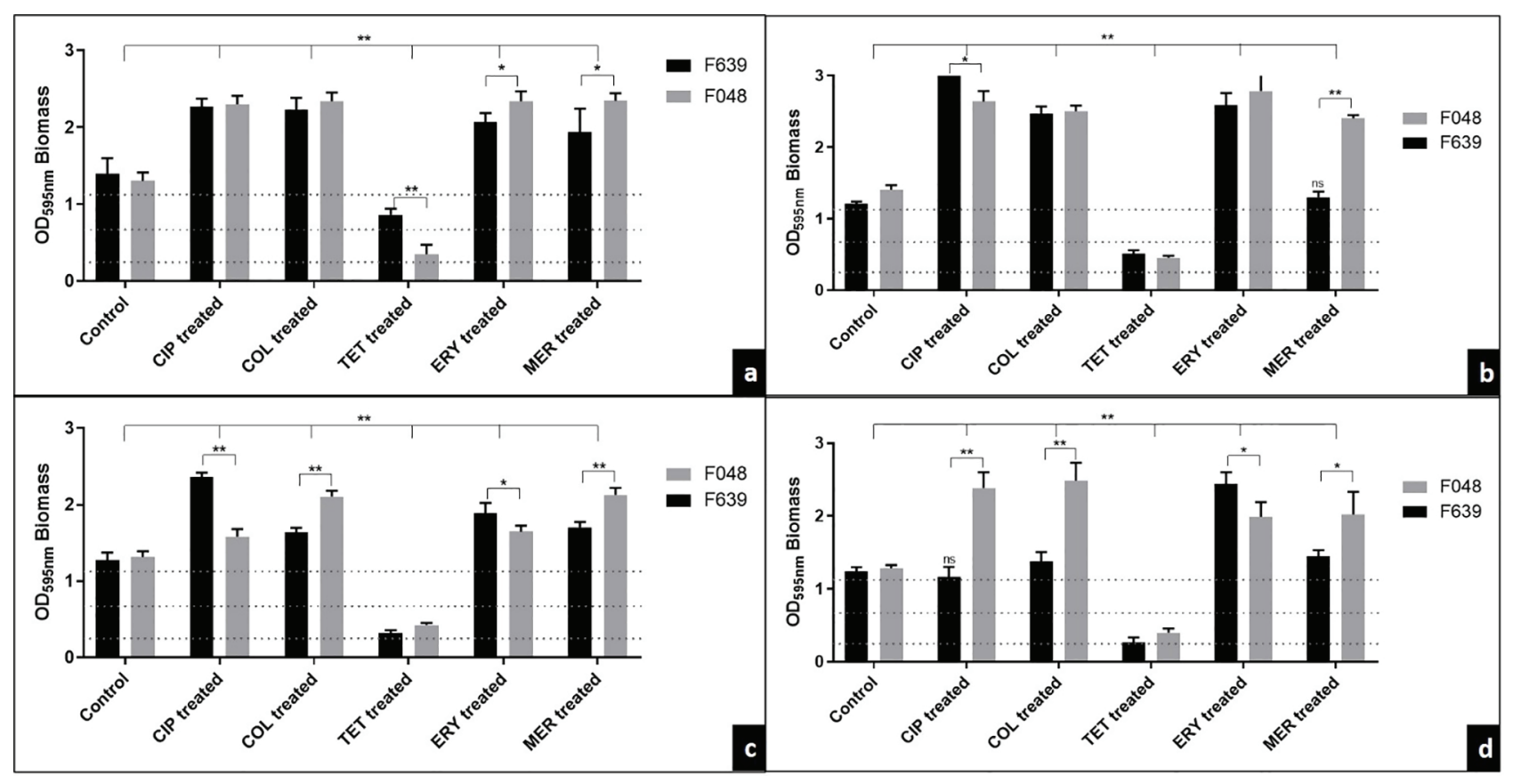

FIGURE 2 | The effect of antibiotic treatment on biofilms supplemented with CJ from two strains of C. jejuni by the traditional method in 96-well microplates (A), on stainless steel (B), polypropylene (C), and polyurethane (D) surfaces. Results represent means with standard deviation (error bars) of three independent experiments with eight replicates. CIP, ciprofloxacin; COL, colistin; TET, tetracycline; ERY, erythromycin; MER, meropenem; Treated, treatment with $32 \mathrm{mg} / \mathrm{L}$ of the antibiotic;.... $\mathrm{BFI}$ classification limits. ns, not significant in relation to the control; ${ }^{\star} \mathrm{p}<0.05 ;{ }^{* *} \mathrm{p}<0.001$ using one way ANOVA.

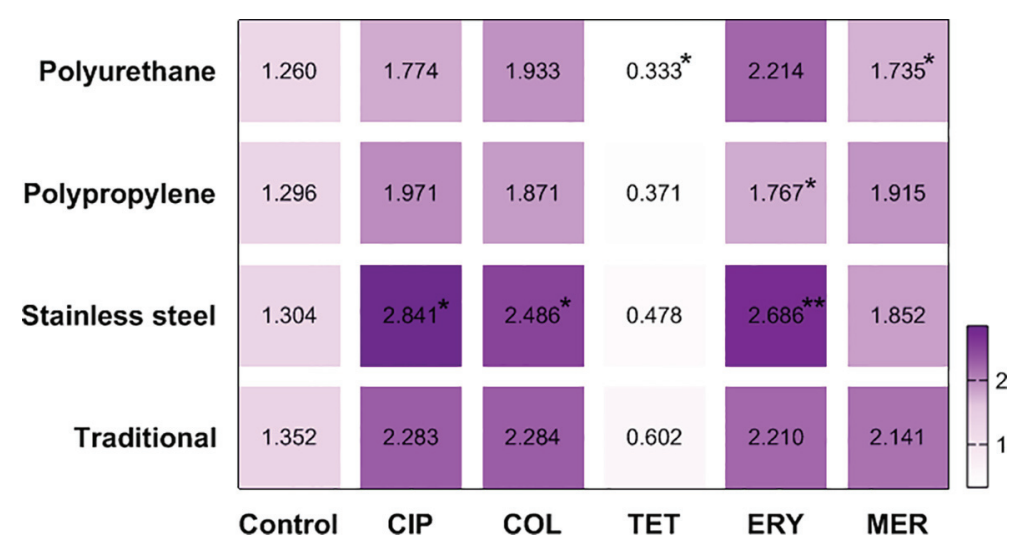

FIGURE 3 | Heat map defined by the average BFI of two strains of $C$. jejuni in different materials after antimicrobial treatment. CIP, ciprofloxacin; COL, colistin; TET, tetracycline; ERY, erytromycin; MER, meropenem; ${ }^{*} p<0.05$; ${ }^{* *} p<0.001$ using Kruskal-Wallis test (GraphPad Prism 8.0.1 software).

C. jejuni, which is a microaerobic and fastidious organism (Siddiqui et al., 2015).

Our study found a high molecular distance between the strains, a result already expected for $C$. jejuni due to its genetic plasticity. Most strains of C. jejuni are naturally competent for the capture of external DNA, so that recombination through transformation becomes a constant event, being the main driver of genetic diversity in this species. This ability resulted in a highly variable clonal population structure so that the boundaries between different groups of related genotypes were difficult to determine (Meric et al., 2014).

In poultry production, bacterial populations are constantly under strong pressure due to temperature variations, the use of antimicrobials, and health control actions. In addition to the high recombinant potential, $C$. jejuni is a bacterium that is phase-variable $(\mathrm{PV})$, which allows the generation of specific genotypes depending on the niche. This happens due to the instability of the polyG regions, whose mutations allow the realization of rearrangements in 

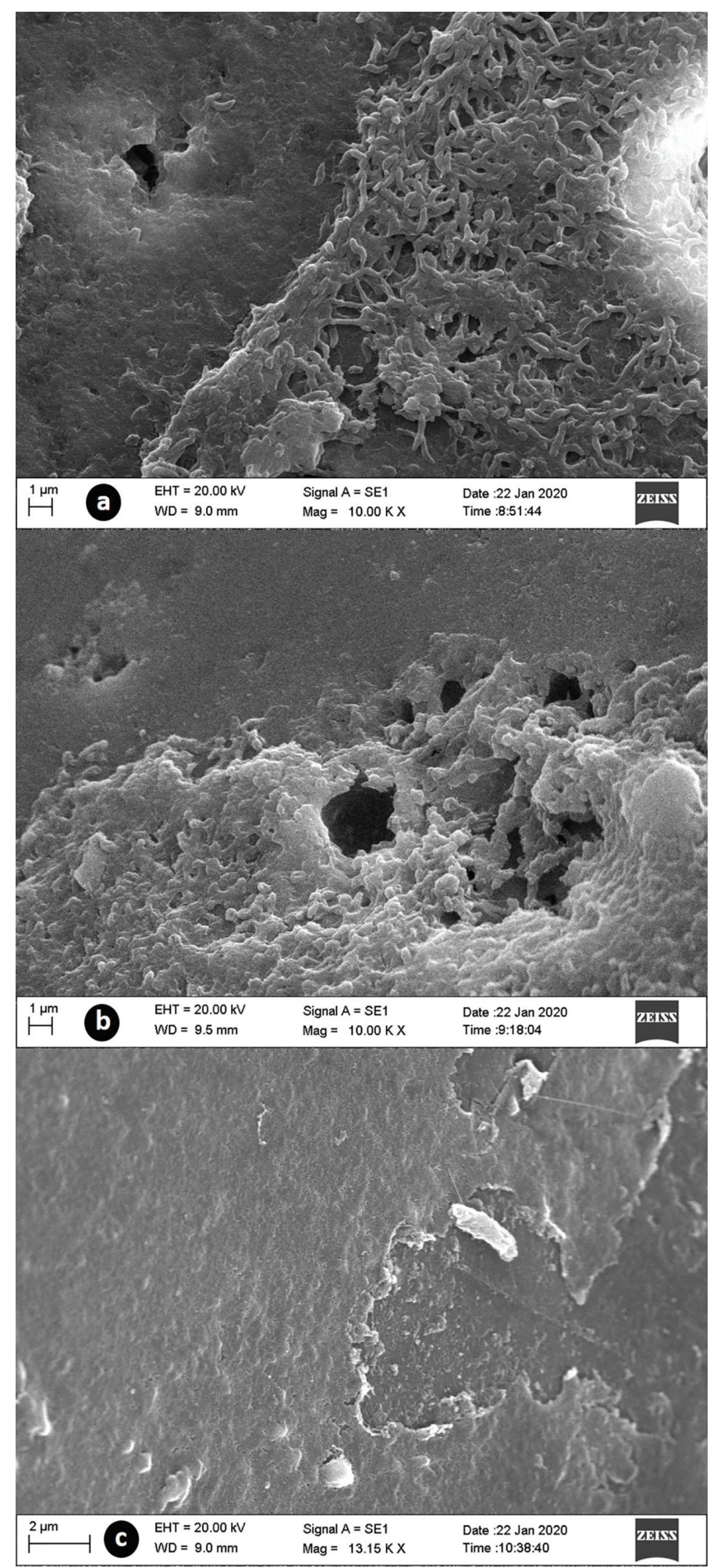

FIGURE 4 | SEM images of biofilms supplemented with CJ from C. jejuni treated with antibiotics at $32 \mathrm{mg} / \mathrm{L}$. (A) control group with normal biofilm structure; (B) treated with meropenem, demonstred the presence of a thick layer of extracellular matrix; (C) treated with tetracycline, with razing of the matrix structure and bacterial exposure. 
the genome and the mobility of fragments (Bayliss et al., 2012), contributing to the observed genetic diversity.

\section{Antimicrobial Resistance Profile in the Planktonic Form}

The alarming concern with antimicrobial resistance has mobilized the various public health entities globally to better understand the problem and to develop strategies of control, especially for C. jejuni. The available antibiotics are becoming less effective, and the high and increasing rates of resistance not only represent an obstacle to the prevention and treatment of the disease, but also increase the cost of health care (Akinkunmi et al., 2014; Elhadidy et al., 2020).

Our findings show that the situation is even more dramatic for ciprofloxacin and tetracycline, with more than $85 \%$ of resistant strains. Ciprofloxacin is a fluoroquinolone of choice for the treatment of campylobacteriosis, however, it is often prescribed as part of empirical treatments for undifferentiated diarrhea in humans. In addition, the use of fluoroquinolones in the late 1990s was extensively expanded in animal husbandry (Iovine, 2013; Kaakoush et al., 2015). Due to the problems associated with antimicrobial resistance, a ban on the use of this class of antimicrobial in Brazil has been enacted since 2009 as a growth promoter or as a preventive medication, but it is still allowed for therapeutic purposes. The use of this drug can promote the selection of resistant bacterial strains in the digestive tract of chickens, which justifies the high percentage of resistance identified and the concordance with results reported in several countries (Di Giannatale et al., 2019; Ilktac et al., 2019; Li et al., 2019).

The class of tetracyclines has been suggested as an alternative drug in the treatment of campylobacteriosis. However, several studies have demonstrated its low efficiency due to the dissemination and easy acquisition of genes for resistance to this antibiotic in the genus Campylobacter. The gene that encodes the tet $O$ ribosomal protection protein of plasmid origin is considered the main responsible for the resistance to tetracyclines, displacing tetracycline from its primary binding site on the ribosome (Elhadidy et al., 2020).

For colistin, the existence of susceptible strains (7/35, 20\%) represents a relevant and discrepant finding in the literature since it is already defined that Campylobacter exhibits intrinsic resistance to polymyxin/colistin, probably due to the absence of appropriate targets and/or low affinity of binding to targets (Iovine, 2013). Despite this finding, some studies have also identified the existence of Campylobacter susceptible to the class of polymyxins (Ghimire et al., 2014; Komba et al., 2015; Khoshbakht et al., 2016). Sorlózano-Puerto et al. (2018) found values low enough (range: $0.38-8 \mathrm{mg} / \mathrm{L}$ ) for colistin sulfate to be considered useful in the treatment of severe diarrhea caused by Campylobacter spp. in an evaluation of 30 strains in Spain. Oral treatment with colistin is indicated in cases of enterocolitis by Gram-negative bacteria, such as pathogenic E. coli because colistin sulfate is poorly absorbed by the gastrointestinal tract and can reach high concentrations in the intestinal lumen (Li et al., 2005). However, there are restrictions on the use of this medicine in human medicine due to its classification by WHO as critically important, being one of the last therapeutic options for certain diseases resulting from bacteria resistant to the drugs of choice (FAO/WHO, 2009). Thus, considering the presence of resistance to ciprofloxacin (5/7) and tetracycline (6/7) in these specific strains, colistin can be used as a treatment option for campylobacteriosis. However, the definition of intrinsic resistance for Campylobacter spp. means that most laboratories (CLSI and EUCAST) do not determine the cutoff points to classify the real susceptibility of this genus to colistin (Sorlózano-Puerto et al., 2018), which makes the results still speculative.

Due to the increasing resistance to fluoroquinolones in Campylobacter, macrolides, such as erythromycin and azithromycin, appear as drugs of choice in the treatment of human campylobacteriosis (Bolinger and Kathariou, 2017). Our results show that erythromycin was the second most efficient antibiotic in the evaluated strains, with a percentage of $34.3 \%$ $(12 / 35)$ of resistance. Despite this, studies show an even greater efficiency with resistance rates ranging from 0 to $17.4 \%$ in several countries (Aksomaitiene et al., 2019; Melo et al., 2019; Otto et al., 2019; Tryjanowski et al., 2019; Elhadidy et al., 2020; Karama et al., 2020). In a contradictory way, it is possible to find high levels of resistance in isolated strains of chickens (AsumingBediako et al., 2019; Pillay et al., 2020). In Brazil, the reduced number of isolates resistant to erythromycin is probably due to decreasing exposure to antibiotics in poultry production after the implementation of a regulatory document that prohibits the use of macrolides in poultry farms.

Despite the low number of resistant strains to meropenem (3/ $35,8.6 \%$ ), compared to other classes, the result is alarming. Meropenem is among the drugs classified as critically important by WHO. Over the past 30 years, carbapenems have played a crucial role in clinical weaponry to treat serious infections in patients primarily affected by multidrug-resistant bacteria. However, the usefulness of this class of antibiotics is being compromised by the emergence of resistance in Enterobacteriaceae and especially in Campylobacteriaceae, being considered as a "nightmare" (Perez et al., 2016; Hagiya et al., 2018). In our study, two of these three strains have erythromycin as a treatment option, but one of them, in addition to resistance to meropenem, was also resistant to all other classes of tested antimicrobials. In cases of refractory infections by Campylobacter, in addition to combination therapy, the use of aminoglycosides is recommended as an alternative for severe cases (Trajkovska-Dokic et al., 2019).

There are statements by EFSA and CDC describing an impending global crisis that may result in a return to the preantibiotic era (CDC, 2015; EFSA, 2020). These serious concerns were catalyzed by the rapid increase in carbapenemase production among bacteria from the Enterobacteriaceae family (Bonomo et al., 2018). For severe infections caused by carbapenemase-producing Enterobacteriaceae, the possibility of treatment is the use of colistin, either singly or in combination with other antibiotics, which does not fit Campylobacter due to its intrinsic resistance (Halaby et al., 2013). Although resistance to carbapenemics in Campylobacter has not yet been well defined 
by the authorities, a study by Hagiya et al. (2018) suggested the existence of resistance due to subsequent exposure to the drug in a clinical situation. Our study demonstrates the first record of phenotypic resistance to meropenem in C. jejuni in Brazil.

Our study revealed that $71.4 \%(25 / 35)$ of the isolates were multidrug-resistant, and if we disregard colistin sulfate, this percentage drops to $37.1 \%$ (13/35). Proportions of less than $40 \%$ have been observed previously in Campylobacter spp. isolated from chickens (Liu et al., 2019; Melo et al., 2019). Values similar to ours were identified by Di Giannatale et al. (2019) in Italy, with $66.15 \%$ of C. jejuni resistant to the same classes of antibiotics tested in our study (ciprofloxacin, tetracycline, and erythromycin).

\section{Antimicrobial Resistance Profile in the Biofilm Forms}

The low efficacy of the drugs tested on the sessile structure had already been detected in other studies that report the influence of antimicrobials stimulating the acquisition of the sessile structure in several species of bacteria, which prevents the drug's effect (Boehm et al., 2009; Kaplan, 2011; Teh et al., 2019).

Our findings make it clear that high concentrations of the drugs were necessary to control the viability of sessile C. jejuni. In addition, it was evident that each strain behaved differently regarding the increased concentration of the antimicrobial necessary to contain the sessile cells in biofilm. This straindependent characteristic was also identified by Teh et al. (2019) when analyzing the action of different classes of antimicrobials against seven strains of sessile C. jejuni. These authors also found that susceptible strains showed a higher production of biofilms compared to resistant strains. We determined that susceptible strains needed a higher concentration of antimicrobials to contain bacterial viability. This difference may be directly related to the nutrient substrate offered to the bacteria in the formation of the biofilm. In our study, we simulated the nutritional conditions of abiotic surfaces present in industry by adding CJ. This substrate stimulated the formation of a more stable, mature, and protein-rich biofilm than that produced only with the use of MH (Melo et al., 2017).

It is also possible that the penetration of antimicrobials by the matrix may have occurred more slowly, which favors the sessile cell, since the gradual exposure generates an adaptive phenotypic response that can potentially increase tolerance to the antimicrobial (Tseng et al., 2013). Another important factor concerns the high rate of mutation detected in sessile cells when compared to planktonic forms, which can contribute to the increase in antimicrobial resistance. Especially for Campylobacter, the genotypic variation resulting from recombination processes already represents an intrinsic factor of the bacteria in the free form and, interestingly, the sessile lifestyle besides promoting high mutation rates also contribute to the emergence of permanently hypermutable strains, as when biofilms are exposed ciprofloxacin, in which the presence of resistant mutants is significantly higher (Bae et al., 2014).

The discrepant results found for tetracycline in our study compared to other antibiotics may be related to the mechanism of action of this antimicrobial agent. This drug has a high diffusion capacity, which allows its use in the treatment of intracellular pathogens (Trabulsi et al., 1999), which probably can facilitate the penetration into the biofilm matrix. For example, tetracycline rapidly reached all cells uropathogenic Escherichia coli (UPEC) biofilms in a study conducted by Stone et al. (2002). In addition, this drug acts on the $30 \mathrm{~S}$ portion of the ribosomes preventing protein synthesis (Trabulsi et al., 1999) and, according to Majtán et al. (2008), antibiotics acting on ribosomes can inhibit the formation of biofilms, interrupting the ability of bacteria to adhere. Considering that C. jejuni biofilms produced with CJ supplementation present a predominantly protein matrix (Melo et al., 2017) it is also possible that tetracycline has influenced the biofilm structure by increasing bacterial exposure.

\section{Effect of Antimicrobials on Biomass}

Overall, all tested antimicrobials altered the biomass of C. jejuni, and in the presence of ciprofloxacin, colistin, erythromycin, and meropenem, this effect was positive, while for tetracycline, it was negative. The susceptibility to antimicrobials, present in the planktonic form of the F048 strain, especially to meropenem, induced a greater stimulation of biomass production, except for tetracycline.

Previous studies have reported that the presence of certain antibiotics influenced the formation of bacterial biofilm in a positive or negative way. For example, ciprofloxacin was shown to induce biofilm formation in Escherichia coli (Rafaque et al., 2020) and Pseudomonas aeruginosa (Soares et al., 2019). Tigecycline favored the formation of biofilm by Staphylococcus epidermidis (Weiser et al., 2016). In Staphylococcus aureus, vancomycin had a positive effect on the acquisition of biofilm form (Pasquaroli et al., 2013). On the other hand, the presence of sub-minimal inhibitory concentrations (MIC) of ciprofloxacin inhibited the biofilms of Salmonella enterica serovar Typhimurium (Majtán et al., 2008).

In our study, we detected significant fluctuations in the IFB of both strains treated on different surfaces and which did not follow a defined pattern. The exception was the treatment with meropenem and erythromycin, which intensified the F048 biomass (susceptible in the planktonic form) in all treatments and in the traditional methodology, respectively. Wild type strains, such as those used in our study, have specific gene expression modulation and modification systems that decisively alter the bacterial phenotype even in minimally different conditions (Teh et al., 2017). Our findings were similar to those by Teh et al. (2019) in C. jejuni, who observed that susceptible strains have a higher production of biofilms compared to resistant strains that reduce their production in the presence of the antibiotics ampicillin, nalidixic acid, erythromycin, rifampicin, and tetracycline. The significant increase in biomass in contact with meropenem has also been described by Navidifar et al. (2019) in susceptible Acinetobacter baumannii strains in planktonic form. The authors attribute this increase to the presence of persistent, metabolically dormant cells, usually present in biofilms. These cells, recently preceded in C. jejuni, are extremely tolerant to antibiotics without 
undergoing any genetic alteration (Morcrette et al., 2020). Another reason for this was suggested in a previous study, which proposed that some antibiotics can act as antagonists of the formation (and growth) of biofilm in low concentrations, agonists in higher concentrations and antagonists in even higher levels (Kaplan, 2011).

Contradictory to our study, Teh et al. (2019) found that, in a general analysis antimicrobials significantly reduce biomass of $C$. jejuni. In our study, this fact was exclusive for biofilms treated with tetracycline. In addition, only for the F639 strain there was no change in the IFB in biofilms produced in stainless steel and polyurethane, treated with meropenem and ciprofloxacin, respectively (Figure 2). The difference may be related to the use of sub-MIC concentrations used by the authors and the type of biofilm produced in our study (protein using CJ).

Kaplan (2011) suggested that there really are variations in the induction or not of biofilm production depending on the antimicrobial used, its concentration, the microorganism, and the composition of the polymeric matrix, performing agonist and antagonist functions and type of contact surface. All of these associated factors contributed to the variations detected in our study.

The surface composition can control the reactivity and binding of substrates, including bacterial extracellular polymers. Stainless steel is the most recommended material for food contact equipment and one of the factors that reinforce this indication is the low porosity and high resistance, in addition to its smooth surface (De Oliveira et al., 2019). However, some of the elements present in this material are favorable to bacterial adhesion, such as iron, manganese and calcium (Arnold and Silvers, 2000), which may justify the influence of stainless steel on the greater intensity of our biofilms treated with ciprofloxacin, colistin and erythromycin. It has been shown that C. jejuni is capable of forming biofilm on a variety of surfaces, including stainless steel, glass and plastics. Stainless steel promotes intensified production due to the high hydrophobicity of the bacterial cell surface that favors the initial cell fixation (Teh et al, 2016). Despite the polyurethane and polypropylene surfaces also showing hydrophobic properties (Iliadis et al., 2018; Vidács et al., 2018), in our work we observed a lower intensity in the biomass produced, with variation dependent on the strain and the antimicrobial. As the cell surface can be modulated by extrinsic characteristics and intrinsic factors, it is possible that exposure to the different conditions tested promoted a variation in hydrophobicity, altering the bacterial adhesion capacity, as identified by Moraes et al. (2019) in Salmonella. Especially for polyurethane, some studies have demonstrated its anti-biofilm effect on Salmonella, S. aureus and P. aeruginosa (Nazli et al., 2019; Brasão et al., 2021).

\section{Structural Change After Antimicrobial Treatment}

The architecture of the biofilms produced showed the same characteristics for both strains in the respective treatments. The observed variations are consistent with the findings obtained in the MIC test and in the biomass assessment. The production of a more expanded and compact structure associated with the absence of bacteria exposed in biofilms treated with antimicrobials, shows that ciprofloxacin, colistin, erythromycin, and meropenem have an agonistic effect on the production of biofilms, causing a stimulus of greater matrix production in order to internally protect bacteria. As for tetracycline, the observed antagonistic effect was directly related to the destruction of the matrix and bacteria, making evident the greater susceptibility of the microorganism.

The variations in the architecture of the biofilms formed were also recorded by Turonova et al. (2015) in different strains of $C$. jejuni and by Melo et al. (2017) on different substrates, with multilayer structures, biofilms with a shape similar to "fingers", with open and spongy ultra-structure, with and without the presence of pores. These reports make it clear that intrinsic and extrinsic factors can influence the structure of $C$. jejuni biofilm.

\section{CONCLUSION}

Our results showed that the presence of susceptible strains to colistin may indicate a new treatment strategy, and that resistance to meropenem detected in three strains is alarming since it is the last therapeutic resource available currently. In biofilms, the high antimicrobial resistance matches the expanded and dense structure of the biomass, except for tetracycline. Susceptible strain in the planktonic form expressed a higher production of biofilms when in contact with the antimicrobial, which is consistent with the need for higher concentrations of the drug for its control compared to resistant strain, except for tetracycline. Stainless steel and polyurethane were the most and least suitable surfaces for the production of treated biomass, respectively. Interestingly, the exceptions pointed out for tetracycline in the biofilm form and for colistin in the planktonic form of C. jejuni affect possible control strategies and, conversely, the existence of resistant meropenem strains may represent an initial threat to public health.

\section{DATA AVAILABILITY STATEMENT}

The datasets generated for this study are available on request to the corresponding author.

\section{AUTHOR CONTRIBUTIONS}

DR wrote sections of the manuscript. CD and VS performed laboratory tests on Campylobacter in free form. AS and MV performed laboratory tests on Campylobacter in sessile form. JS performed laboratory tests on Campylobacter in sessile form in different materials. RP performed the phylogenetic analysis of the strains. GM and CM contributed to the statistical analysis of the data, translation of the manuscript and methodological guidance. JS wrote the final draft of the manuscript. RM revised 
the final draft of the manuscript, organized the database, performed the test in SEM, contributed to the conception and design of the study. All authors contributed to the article and approved the submitted version.

\section{REFERENCES}

Abushaheen, M. A., Muzaheed,, Fatani, A. J., Alosaimi, M., Mansy, W., George, M., et al. (2020). Antimicrobial Resistance, Mechanisms and Its Clinical Significance. Dis. Mon. 66 (6), 100971. doi: 10.1016/j.disamonth.2020.100971

Akinkunmi, E. O., Adesunkanmi, A. R., and Lamikanra, A. (2014). Pattern of Pathogens From Surgical Wound Infections in a Nigerian Hospital and Their Antimicrobial Susceptibility Profiles. Afr Health Sci. 14 (4), 802-809. doi: 10.4314/ahs.v14i4.5

Akopyanz, N., Bukanov, N. O., Westblom, T. U., Kresovich, S., and Berg, D. E. (1992). DNA Diversity Among Clinical Isolates of Helicobacter Pylori Detected by PCR-Based RAPD Fingerprinting. Nucleic Acids Res. 20 (19), 5137-5142. doi: $10.1093 / \mathrm{nar} / 20.19 .5137$

Aksomaitiene, J., Ramonaite, S., Tamuleviciene, E., Novoslavskij, A., Alter, T., and Malakauskas, M. (2019). Overlap of Antibiotic Resistant Campylobacter Jejuni MLST Genotypes Isolated From Humans, Broiler Products, Dairy Cattle and Wild Birds in Lithuania. Front. Microbiol. 10, 1377. doi: 10.3389/fmicb.2019.01377

Arnold, J. W., and Silvers, S. (2000). Comparison of Poultry Processing Equipment Surfaces for Susceptibility to Bacterial Attachment and Biofilm Formation. Poultry Science. 79 (8), 1215-1221. doi: 10.1093/ps/79.8.1215

Associação Brasileira de Proteina Animal-ABPA (2020). Relatórios Anuais: Relatório Anual 2020. Available at: https://abpa-br.org/wp-content/uploads/2020/05/abpa_ relatorio_anual_2020_portugues_web.pdf (Accessed Acessed January 21, 2021).

Asuming-Bediako, N., Parry-Hanson, K. A., Abraham, S., and Habib, I. (2019). Campylobacter At the Human-Food Interface: The African Perspective. Pathogens. 8 (2), 87. doi: 10.3390/pathogens 8020087

Bae, J., Oh, E., and Jeon, B. (2014). Enhanced Transmission of Antibiotic Resistance in Campylobacter Jejuni Biofilms by Natural Transformation. Antimicrob. Agents Ch. 58 (12), 7573-7575. doi: 10.1128/AAC.04066-14

Bayliss, C. D., Bidmos, F. A., Anjum, A., Manchev, V. T., Richards, R. L., and Grossier, J. P. (2012). Phase Variable Genes Of Campylobacter Jejuni Exhibit High Mutation Rates and Specific Mutational Patterns But Mutability is Not the Major Determinant of Population Structure During Host Colonization. Nucleic Acids Res. 40 (13), 5876-5889. doi: 10.1093/nar/gks246

Birk, T., Rosenquist, H., Brondsted, L., Ingmer, H., Bysted, A., Christensen, B. B., et al. (2006). A Comparative Study of Two Food Model Systems to Test the Survival Of Campylobacter Jejuni At -18 Degrees C. J. Food Prot. 69 (11), 2635-2639. doi: 10.4315/0362-028X-69.11.2635

Boehm, A., Steiner, S., Zaehringer, F., Casanova, A., Hamburger, F., Ritz, D., et al. (2009). Second Messenger Signalling Governs Escherichia Coli Biofilm Induction Upon Ribosomal Stress. Mol. Microbiol. 72 (6), 1500-1516. doi: 10.1111/j.1365-2958.2009.06739.x

Bolinger, H., and Kathariou, S. (2017). The Current State of Macrolide Resistance in Campylobacter Spp.: Trends and Impacts of Resistance Mechanisms. Appl. Environ. Microbiol. 83 (12), 00416-00417. doi: 10.1128/AEM.00416-17

Bonomo, R. A., Burd, E. M., Conly, J., Limbago, B. M., Poirel, L., Segre, J. A., et al. (2018). Carbapenemase-Producing Organisms: A Global Scourge. Clin. Infect. Dis. 3, 66 (8), 1290-1297. doi: 10.1093/cid/cix893

Brasão, S. C., Melo, R. T., Prado, R. R., Monteiro, G. P., Santos, F. A. L., Braz, R. F., et al. (2021). Characterization and Control of Biofilms of Salmonella Minnesota of Poultry Origin. Food Biosc. 39, 100811. doi: 10.1016/j.fbio.2020.100811

Brown, H. L., Reuter, M., Salt, L. J., Cross, K. L., Betts, R. P., and van Vliet, A. H. M. (2014). Chicken Juice Enhances Surface Attachment and Biofilm Formation of Campylobacter Jejuni. Appl. Environ. Microbiol. 80, 7053-7060. doi: 10.1128/ AEM.02614-14

Center for Disease Control and Prevention-CDC (2015). Nacional Center for Emerging and Zoonotic Infectious Diseases. Available at: http://www.cdc.gov/nczved/ divisions/dfbmd/siseases/campylobacter (Accessed January 17, 2020).

Centers for Disease Control and Prevention-CDC (2020). National Center for Emerging and Zoonotic Infectius Disease. Campylobacteriosis 1, 720. https:// wwwnc.cdc.gov/travel/yellowbook/2020/travel-related-infectious-diseases/ campylobacteriosis. [Accessed January 21, 2021].

\section{ACKNOWLEDGMENTS}

To CNPq, FAPEMIG and CAPES (Finance Code 001) for financial support for the execution of the study.

de Oliveira, A. P., Webber, B., Pottker, E. S., Daroit, L., dos Santos, L. R., and Rodrigues, L. B. (2019). Salmonella Enteritidis Adhesion Involved in Food Outbreaks Under Different Surfaces and Environmental Conditions. (In Portuguese) Sci Plen. 15 (11), 1-9. doi: 10.14808/sci.plena.2019.116101

Di Giannatale, E., Calistri, P., Di Donato, G., Decastelli, L., Goffredo, E., and Adriano, D. (2019). Thermotolerant Campylobacter Spp. in Chicken and Bovine Meat in Italy: Prevalence, Level of Contamination and Molecular Characterization of Isolates. PloS One 14 (12), 225957. doi: 10.1371/ journal.pone.0225957

Elhadidy, M., Ali, M. M., El-Shibiny, A., Miller, W. G., Elkhatib, W. F., Botteldoorn, N., et al. (2020). Antimicrobial Resistance Patterns and Molecular Resistance Markers of Campylobacter Jejuni Isolates From Human Diarrheal Cases. PloS One 15 (1), 227833. doi: 10.1371/journal.pone.0227833

European Committee on Antimicrobial Susceptibility Testing-EUCAST (2020). Breakpoint Tables for Interpretation of Mics and Zone Diameters, Version 11.0. Available at: https://eucast.org/clinical_breakpoints/ (Accessed January 15, 2020).

European Food Safety Authority-EFSA (2020). The European Union Summary Report on Antimicrobial Resistance in Zoonotic and Indicator Bacteria From Humans, Animals and Food in 2017/2018. EFSA J. Parma Italy 18 (3), 6007. doi: $10.2903 /$ j.efsa.2020.6007

European Food Safety Authority, European Centre for Disease Prevention and Control-EFSA-ECDC (2015). EU Summary Report on Antimicrobial Resistance in Zoonotic and Indicator Bacteria From Humans, Animals and Food in 2013. EFSA J. 13 (2), 4036. doi: 10.2903/j.efsa.2015.4036

Food and Agriculture Organization/World Health Organization-FAO/WHO (2009) Salmonella and Campylobacter in Chicken Meat (Rome). Available at: http://www.fao.org/3/a-i1133e.pdf (Accessed January 20, 2020).

Ghimire, L., Singh, D. K., Basnet, H. B., Bhattarai, R. K., Dhakal, S., and Sharma, B. (2014). Prevalence, Antibiogram and Risk Factors of Thermophilic Campylobacter Spp. in Dressed Porcine Carcass of Chitwan, Nepal. BMC Microbiol. 14, 85. doi: 10.1186/1471-2180-14-85

Goodfellow, J. A., and Willison, H. J. (2016). Guillain-Barre Syndrome: A Century of Progress. Nat. Rev. Neurol. 12 (12), 723-731. doi: 10.1038/nrneurol.2016.172

Hagiya, H., Kimura, K., Nishi, I., Yoshida, H., Yamamoto, N., Akeda, Y., et al. (2018). Emergence of Carbapenem Non-Susceptible Campylobacter Coli After Long-Term Treatment Against Recurrent Bacteremia in a Patient With XLinked Agammaglobulinemia. Ann. Intern. Med. 57 (14), 2077-2080. doi: 10.2169/internalmedicine.0312-17

Halaby, T., Al Naiemi, N., Kluytmans, J., Van Der Palen, J., and VandenbrouckeGrauls, C. M. (2013). Emergence of Colistin Resistance in Enterobacteriaceae After the Introduction of Selective Digestive Tract Decontamination in an Intensive Care Unit. Agents Chemother. 57 (7), 3224-3229. doi: 10.1128/AAC.02634-12

Hall, C. W., and Mah, T. F. (2017). Molecular Mechanisms of Biofilm-Based Antibiotic Resistance and Tolerance in Pathogenic Bacteria. FEMS Microbiol. Rev. 41 (3), 276-301. doi: 10.1093/femsre/fux010nbsp

Harmon, K. M., Ramsom, G. M., and Wesley, I. V. (1997). Differentiation of Campylobacter Jejuni and Campylobacter Coli by Polymerase Chain Reaction. Mol. Cell Probes. 11, 195-200. doi: 10.1006/mcpr.1997.0104

Iliadis, I., Daskalopoulou, A., Simões, M., and Giaouris, E. (2018). Integrated Combined Effects of Temperature, $\mathrm{Ph}$ and Sodium Chloride Concentration on Biofilm Formation by Salmonella Enterica Ser. Enteritidis and Typhimurium Under Low Nutrient Food-Related Conditions. Food Res. Int. 107, 10-18. doi: 10.1016/j.foodres.2018.02.015

Ilktac, M., Ongen, B., Humphrey, T. J., and Williams, L. K. (2019). Molecular and Phenotypical Investigation of Ciprofloxacin Resistance Among Campylobacter Jejuni Strains of Human Origin: High Prevalence of Resistance in Turkey. APMIS. 128 (1), 41-47. doi: 10.1111/apm.13005

International Standards Organization (2006). ISO 10272-1: Microbiology of Food and Animal Feeding Stuffs - Horizontal Method for Detection and Enumeration of Campylobacter Spp. Part 1: detection method ISO 10272-1, 2006.

Iovine, N. M. (2013). Resistance Mechanisms in Campylobacter Jejuni. Virulence. 4 (3), 230-240. doi: 10.4161/viru.23753 
Kaakoush, N. O., Castaño-Rodríguez, N., Mitchell, H. M., and Man, S. M. (2015). Global Epidemiology of Campylobacter Infection. Clin. Microbiol. Rev. 28 (3), 687-720. doi: 10.1128/CMR.00006-15

Kaplan, J. B. (2011). Antibiotic-Induced Biofilm Formation. Artif. Organs. 34 (9), 737-751. doi: 10.5301/ijao.5000027

Karama, M., Kambuyi, K., Cenci-Goga, B. T., Malahlela, M., Jonker, A., He, C., et al. (2020). Occurrence and Antimicrobial Resistance Profiles of Campylobacter Jejuni, Campylobacter Coli, And Campylobacter Upsaliensis in Beef Cattle on Cow-Calf Operations in South Africa. Foodborne Pathog. Dis. 17 (9), 440-446. doi: 10.1089/fpd.2019.2703

Khoshbakht, R., Tabatabaei, M., Hoseinzadeh, S., Raeisi, M., Shirzad, A. H., and Berizi, E. (2016). Prevalence and Antibiotic Resistance Profile of Thermophilic Campylobacter Spp. of Slaughtered Cattle and Sheep in Shiraz, Iran. Vet. Res. Forum. 7 (3), 241-246.

Klein-Jobstl, D., Sofka, D., Iwersen, M., Drillich, M., and Hilbert, F. (2016). Multilocus Sequence Typing and Antimicrobial Resistance of Campylobacter Jejuni Isolated From Dairy Calves in Austria. Front. Microbiol. 7, 72. doi: $10.3389 /$ fmicb.2016.00072

Komba, E. V. G., Mdegela, R. H., Msoffe, P. L. M., Nielsen, L. N., and Ingmer, H. (2015). Prevalence, Antimicrobial Resistance and Risk Factors for Thermophilic Campylobacter Infections in Symptomatic and Asymptomatic Humans in Tanzania. Zoonoses Public Health 62 (7), 557-568. doi: 10.1111/ zph.12185

Li, Y., Gu, Y., Lv, J., Liang, H., Zhang, J., Zhang, S., et al. (2019). Laboratory Study on the Gastroenteritis Outbreak Caused by a Multidrug-Resistant Campylobacter Coli in China. Foodborne Pathog. Dis. 17 (3), 187-193. doi: 10.1089/ fpd.2019.2681

Li, J., Nation, R. L., Milne, R. W., Turnidge, J. D., and Coulthard, K. (2005). Evaluation of Colistin as an Agent Against Multi-Resistant Gram-Negative Bacteria. Int. J. Antimicrob. Agents. 25 (1), 11-25. doi: 10.1016/j.ijantimicag. 2004.10.001

Liu, D., Li, X., Liu, W., Yao, H., Liu, Z., Febler, A. T., et al. (2019). Characterization Of Multiresistance Gene Cfr(C) Variants In Campylobacter From China. J. Antimicrob. Chemother. 74 (8), 2166-2170. doi: 10.1093/jac/dkz197

Majtán, J., Majtánová, E. U., Xu, M., and Majtán, V. (2008). In Vitro Effect of Subinhibitory Concentrations of Antibiotics on Biofilm Formation by Clinical Strains of Salmonella Enterica Serovar Typhimurium Isolated in Slovakia. J. Appl. Microbiol. 104 (5), 1294-1301. doi: 10.1111/j.1365-2672.2007.03653.x

Mazurier, S. I., Audurier, A., Marquet-Van der Mee, N., Notermans, S., and Wernars, K. (1992). A Comparative Study of Randomly Amplified Polymorphic DNA Analysis and Conventional Phage Typing for Epidemiological Studies of Lisferia Monocytogenes Isolates. Res. Microbiol. 143, 507-512. doi: 10.1016/0923-

Melo, R. T., Grazziotin, A. L., Valadares Júnior, E. C. V., Prado, R. R., Mendonça, E. P., Monteiro, G. P., et al. (2019). Evolution Of Campylobacter Jejuni of Poultry Origin in Brazil. Food Microbiol. 82, 489-496. doi: 10.1016/j.fm.2019.03.009

Melo, R. T., Mendonça, E. P., Monteiro, G. P., Siqueira, M. C., Pereira, C. B., Peres, P. A. B. M., et al. (2017). Intrinsic and Extrinsic Aspects On Campylobacter Jejuni Biofilms. Front. Microbiol. 8, 1332. doi: 10.3389/fmicb.2017.01332

Meric, G., Yahara, K., Mageiros, L., Pascoe, B., Maiden, M. C. J., Jolley, K. A., et al. (2014). A Reference Pan-Genome Approach to Comparative Bacterial Genomics: Identification of Novel Epidemiological Markers in Pathogenic Campylobacter. PloS One 9 (3), 92798. doi: 10.1371/journal.pone.0092798

Moraes, J. O., Cruz, E. A., Pinheiro, Í., Oliveira, T. C., Alvarenga, V., Sant'Ana, A. S., et al. (2019). An Ordinal Logistic Regression Approach to Predict the Variability on Biofilm Formation Stages by Five Salmonella Enterica Strains on Polypropylene and Glass Surfaces as Affected by $\mathrm{Ph}$, Temperature and Nacl. Food Microbiol. 83, 95-103. doi: 10.1016/j.fm.2019.04.012

Morcrette, H., Kovacs-Simon, A., Tennant, R. K., Love, J., Wagley, S., Yang, Z. R., et al. (2020). Campylobacter Jejuni 11168H Exposed to Penicillin Forms Persister Cells and Cells With Altered Redox Protein Activity. Front. Cell Infect. Microbiol. 10, 565975. doi: 10.3389/fcimb.2020.565975

Naves, P., Del Prado, G., Huelves, L., Gracia, M., Ruiz, V., Blanco, J., et al. (2008). Measurement of Biofilm Formation by Clinical Isolates of Escherichia Coli is Method-Dependent. J. Appl. Microbiol. 105, 585-590. doi: 10.1111/j.13652672.2008.03791.x

Navidifar, T., Amin, M., and Rashno, M. (2019). Effects of Sub-Inhibitory Concentrations of Meropenem and Tigecycline on the Expression of Genes
Regulating Pili, Efflux Pumps and Virulence Factors Involved in Biofilm Formation by Acinetobacter Baumannii. Infect. Drug Resist. 7 (12), 10991111. doi: 10.2147/IDR.S199993

Nazlı, O., Baygar, T., Dönmez, Ç.E.D., Dere, Ö., Uysal, A.İ., Aksözek, A., et al. (2019). Antimicrobial and Antibiofilm Activity of Polyurethane/Hypericum Perforatum Extract (PHPE) Composite. Bioorg Chem. 82, 224-228. doi: 10.1016/j.bioorg.2018.08.017

Otto, S. J. G., Levett, P. N., Reid-Smith, R. J., Pearl, D. L., Daku, D., Nagle, E., et al. (2019). Antimicrobial Resistance of Human Campylobacter Species Infections in Saskatchewan, Canad-2006): A Historical Provincial Collection of All Reported Cases. Foodborne Pathog. Dis. doi: 10.1089/fpd.2019.2707

Pasquaroli, S., Zandri, G., Vignaroli, C., Vuotto, C., Donelli, G., and Biavasco, F. (2013). Antibiotic Pressure Can Induce the Viable But Non-Culturable State in Staphylococcus Aureus Growing in Biofilms. J. Antimicrob. Chemother. 68 (8), 1812-1817. doi: $10.1093 / \mathrm{jac} / \mathrm{dkt} 086$

Perez, F., Chakhtoura, N. G. E., Papp-Wallace, K., Wilson, B. M., and Bonomo, R. A. (2016). Treatment Options for Infections Caused by CarbapenemResistant Enterobacteriaceae: Can We Apply "Precision Medicine" to Antimicrobial Chemotherapy? Expert Opin. Pharmacother. 17 (6), 761-781. doi: $10.1517 / 14656566.2016 .1145658$

Perio, M. A., Niemeier, R. T., Levine, S. J., Gruszynski, K., and Gibbins, J. D. (2013). Campylobacter Infection in Poultry-Processing Workers-2011. Emerg. Infect. Dis. 19, 286-288. doi: 10.3201/eid1902.121147

Pillay, S., Amoako, D. G., Abia, A. L. K., Somboro, A. M., Shobo, C. O., Perrett, K., et al. (2020). Characterisation Of Campylobacter Spp. Isolated From Poultry in Kwazulu-Natal, South Africa. Antibiotics. 9 (2), 42. doi: 10.3390/ antibiotics 9020042

Rafaque, Z., Abid, N., Liaqat, N., Afridi, P., Siddique, S., Masood, S., et al. (2020). In-Vitro Investigation of Antibiotics Efficacy Against Uropathogenic Escherichia Coli Biofilms and Antibiotic Induced Biofilm Formation At SubMinimum Inhibitory Concentration of Ciprofloxacin. Infect. Drug Resist. 12 (13), 2801-2810. doi: 10.2147/IDR.S258355

Siddiqui, F. M., Akram, M., Noureen, N., Noreen, Z., and Bokhari, H. (2015). Antibiotic Susceptibility Profiling and Virulence Potential Of Campylobacter Jejuni Isolates From Different Sources in Pakistan. Asian Pac J. Trop. Med. 8 (3), 197-202. doi: 10.1016/S1995-7645(14)60314-X

Soares, A., Roussel, V., Pestel-Caron, M., Barreau, M., Caron, F., Bouffartigues, E., et al. (2019). Understanding Ciprofloxacin Failure in Pseudomonas Aeruginosa Biofilm: Persister Cells Survive Matrix Disruption. Front. Microbiol. 13 (10), 2603. doi: 10.3389/fmicb.2019.02603

Sorlózano-Puerto, A., Carrillo, Á.J.A., Gutiérrez-Soto, M., Navarro, J. M., and Gutiérrez-Fernández, J. (2018). Susceptibility of Clinical Isolates of Campylobacter Jejuni and Campylobacter Coli to Colistin. New Microbiol. 41 (3), 235-237.

Stone, G., Wood, P., Dixon, L., Keyhan, M., and Matin, A. (2002). Tetracycline Rapidly Reaches All the Constituent Cells of Uropathogenic Escherichia Coli Biofilms. Antimicrob. Agents Ch. 46, 2458-2461. doi: 10.1128/AAC.46.8.2458-2461.2002

Sulaeman, S., Hernould, M., Schaumann, A., Coquet, L., Bolla, J. M., Dé, E., et al. (2012). Enhanced Adhesion of Campylobacter Jejuni to Abiotic Surfaces is Mediated by Membrane Proteins in Oxygen-Enriched Conditions. PloS One 7, 46402. doi: 10.1371/journal.pone.0046402

Tang, Y., Sahin, O., Pavlovic, N., Lejeune, J., Carlson, J., Wu, Z., et al. (2017). Rising Fuoroquinolone Resistance in Campylobacter Isolated From Feedlot Cattle in the United States. Sci. Rep. 7 (1), 494. doi: 10.1038/s41598-017-00584-Z

Teh, A. H. T., Lee, S. M., and Dykes, G. A. (2016). The Influence of Prior Modes of Growth, Temperature, Medium, and Substrate Surface on Biofilm Formation by Antibiotic-Resistant Campylobacter Jejuni. Curr. Microbiol. 73, 859-866. doi: 10.1007/s00284-016-1134-5

Teh, A. H. T., Lee, S. M., and Dykes, G. A. (2017). Identification of Potential Campylobacter Jejuni Genes Involved in Biofilm Formation by EZ-Tn5 Transposome Mutagenesis. BMC Res. notes. 10 (1), 182. doi: 10.1186/ s13104-017-2504-1

Teh, A. H. T., Lee, S. M., and Dykes, G. A. (2019). Growth in the Presence of Specific Antibiotics Induces Biofilm Formation by a Campylobacter Jejuni Strain Sensitive to Them But Not in Resistant Strains. J. Glob Antimicrob. Resist. 18, 55-58. doi: 10.1016/j.jgar.2019.05.020

Trabulsi, L. R., Mimica, I., and Mimica, L. M. J. (1999). Características Dos Principais Grupos De Antibacterianos: Espectro De Ação E Indicações. (in Portuguese). 3z.ausco; Ed. Microbiol. (Atheneu, São Paulo) 5, 87-91. 99-109. 
Trajkovska-Dokic, E., Mihajlov, K., Mirchevska, G., Kostovski, M., Blazevska, A., and Stojkovska, S. (2019). Antimicrobial Susceptibility of Campylobacter Isolates in the Capital of North Macedonia. Pril (Makedon Akad Nauk Umet Odd Med. Nauki). 40 (2), 73-80. doi: 10.2478/prilozi-2019-0017

Tryjanowski, P., Nowakowski, J. J., Indykiewicz, P., Andrzejewska, M., Spica, D., Sandecki, R., et al. (2019). Campylobacter in Wintering Great Tits Parus Major in Poland. Environ. Sci. Pollut. Res. Int. 27, 7570-7577. doi: 10.1007/s11356019-07502-y

Tseng, B. S., Zhang, W., Harrison, J. J., Quach, T. P., Song, J. L., Penterman, J., et al. (2013). The Extracellular Matrix Protects Pseudomonas Aeruginosa Biofilms by Limiting the Penetration of Tobramycin. Environ. Microbiol. (10), 28652878. doi: 10.1111/1462-2920.12155

Turonova, H., Briandet, R., Rodrigues, R., Hernould, M., Hayek, N., Stintzi, A., et al. (2015). Biofilm Spatial Organization by the Emerging Pathogen Campylobacter Jejuni: Comparison Between NCTC 11168 and 81-176 Strains Under Microaerobic and Oxygen-Enriched Conditions. Front. Microbiol. 6, 709. doi: 10.3389/fmicb.2015.00709

Vidács, A., Kerekes, E., Rajkó, R., Petkovits, T., Alharbi, N. S., Khaled, C., et al. (2018). Optimization of Essential Oil-Based Natural Disinfectants Against Listeria Monocytogenes and Escherichia Coli Biofilms Formed on Polypropylene Surfaces. J. Mol. Liq. 255 (1), 257-262. doi: 10.1016/j.molliq.2018.01.179

Weiser, J., Henke, H. A., Hector, N., Both, A., Christner, M., Büttner, H., et al. (2016). Sub-Inhibitory Tigecycline Concentrations Induce Extracellular Matrix Binding Protein Embp Dependent Staphylococcus Epidermidis Biofilm
Formation and Immune Evasion. Int. J. Med. Microbiol. 306 (6), 471-478. doi: 10.1016/j.ijmm.2016.05.015

World Health Organization-WHO (2017a). Global Priority List of AntibioticResistant Bacteria to Guide Research, Discovery, and Development of New Antibiotics. Available at: https://www.who.int/medicines/publications/WHOPPL-Short_Summary_25Feb-ET_NM_WHO.pdf?ua=1 (Accessed January 20, 2020).

World Health Organization-WHO (2017b). Prioritization of Pathogens to Guide Discovery, Research and Development of New Antibiotics for DrugResistant Bacterial Infections, Including Tuberculosis (Geneva: World Health Organization). (WHO/EMP/IAU/2017.12). Licence: CC BY-NCSA 3.0 IGO.

Conflict of Interest: The authors declare that the research was conducted in the absence of any commercial or financial relationships that could be construed as a potential conflict of interest.

Copyright (C) 2021 Rossi, Dumont, Santos, Vaz, Prado, Monteiro, Melo, Stamoulis, Santos and Melo. This is an open-access article distributed under the terms of the Creative Commons Attribution License (CC BY). The use, distribution or reproduction in other forums is permitted, provided the original author(s) and the copyright owner(s) are credited and that the original publication in this journal is cited, in accordance with accepted academic practice. No use, distribution or reproduction is permitted which does not comply with these terms. 